\title{
Fusion Tyrosine Kinase NPM-ALK Deregulates MSH2 and Suppresses DNA Mismatch Repair Function
}

\section{Novel Insights into a Potent Oncoprotein}

Leah C. Young, ${ }^{*}$ Kathleen M. Bone, ${ }^{*}$ Peng Wang, ${ }^{*}$ Fang Wu, ${ }^{\dagger}$ Benjamin A. Adam, ${ }^{*}$ Samar Hegazy, ${ }^{*}$ Pascal Gelebart, ${ }^{*}$ Jelena Holovati, ${ }^{,}$Liang Li, ${ }^{\dagger}$ Susan E. Andrew, ${ }^{\star}$ and Raymond Lai, ${ }^{* \S}$

From the Departments of Laboratory Medicine and Pathology," Chemistry, ${ }^{\dagger}$ and Medical Genetics, ${ }^{\ddagger}$ University of Alberta, Edmonton, Alberta; and DynaLIFE ${ }_{\mathrm{DX}}$ Medical Laboratories, ${ }^{\S}$ Edmonton, Alberta, Canada

The fusion tyrosine kinase NPM-ALK is central to the pathogenesis of ALK-positive anaplastic large cell lymphoma ( $\left.\mathrm{ALK}^{+} \mathrm{ALCL}\right)$. We recently identified that MSH2, a key DNA mismatch repair (MMR) protein integral to the suppression of tumorigenesis, is an NPM-ALK-interacting protein. In this study, we found in vitro evidence that enforced expression of NPM-ALK in HEK293 cells suppressed MMR function. Correlating with these findings, six of nine ALK ${ }^{+}$ALCL tumors displayed evidence of microsatellite instability, as opposed to none of the eight normal DNA control samples $(P=0.007$, Student's $t$-test). Using co-immunoprecipitation, we found that increasing levels of NPM-ALK expression in HEK293 cells resulted in decreased levels of MSH6 bound to MSH2, whereas MSH2-NPM-ALK binding was increased. The NPM-ALK-MSH2 interaction was dependent on the activation/autophosphorylation of NPM-ALK, and the Y191 residue of NPM-ALK was a crucial site for this interaction and NPM-ALK-mediated MMR suppression. MSH2 was found to be tyrosine phosphorylated in the presence of NPM-ALK. Finally, NPMALK impeded the expected DNA damage-induced translocation of MSH2 out of the cytoplasm. To conclude, our data support a model in which the suppression of MMR by NPM-ALK is attributed to its ability to interfere with normal MSH2 biochemistry and function. (Am J Pathol 2011, 179:411-421; DOI: 10.1016/j.ajpath.2011.03.045)
NPM-ALK is an oncogenic fusion tyrosine kinase found exclusively in ALK-positive anaplastic large-cell lymphoma (ALK $\left.{ }^{+} A L C L\right)$, a lymphoid malignancy of mature T/null immunophenotype occurring most frequently in children..$^{1,2}$ The fusion gene encoding NPM-ALK is a consequence of the reciprocal chromosomal translocation $t(2 ; 5)(p 23 ; q 35)$ that fuses the promoter and $5^{\prime}$ portion of the nucleophosmin (NPM) gene directly upstream of the DNA segment encoding the kinase domain of the anaplastic lymphoma kinase (ALK) gene (reviewed by Amin and $\mathrm{Lai}^{3}$ ). Normally, the tyrosine kinase activity of ALK is controlled by ligand binding, and the expression of the ALK receptor tyrosine kinase is restricted to a subset of neuronal cells. In contrast, the expression of NPM-ALK in ALK ${ }^{+} A L C L$ cells is driven by the strong and ubiquitous NPM promoter; the tyrosine kinase embedded in NPM-ALK is constitutively phosphorylated and activated via its dimerization mediated through the NPM oligomerization domain. ${ }^{4}$ The expression of NPM-ALK has been shown to be sufficient to promote malignant transformation, in both cell lines and murine models. ${ }^{5-8}$ The mechanisms underlying its oncogenic potential are attributed to the fact that NPM-ALK phosphorylates and deregulates a host of cellular signaling proteins, which often

Supported by research grants from the Alberta Cancer Foundation and the Canadian Institutes of Health Research (R.L.). S.E.A is an Alberta Heritage Foundation for Medical Research Senior Scholar. K.M.B. is a recipient of the Izaak Walton Killam Memorial Scholarship (University of Alberta). B.A.A. was supported by a summer studentship provided by the Alberta Heritage Foundation for Medical Research. L.L. is a Canada Research Chair in Chemistry.

Accepted for publication March 10, 2011.

Supplemental material for this article can be found at http://ajp. amjpathol.org or at doi: 10.1016/j.ajpath.2011.03.045.

Address reprint requests to Raymond Lai, M.D., Ph.D., 11560 University Avenue, Room 2338, Department of Laboratory Medicine and Pathology, Cross Cancer Institute and University of Alberta, Edmonton, AB, Canada T6G 1Z2. E-mail: rlai@ualberta.ca. 
leads to cell cycle progression and suppression of apoptosis (reviewed by Amin and $\mathrm{Lai}^{3}$ ).

To further explore the scope of NPM-ALK oncogenic pressure, we recently used tandem affinity purified NPMALK and mass spectrometry to generate a comprehensive catalogue of proteins that interact with NPM-ALK. ${ }^{9}$ We found that NPM-ALK binds to a large number of proteins that are involved in a great diversity of biological functions. Specifically, we found that the DNA mismatch repair (MMR) protein MSH2, but not its normal binding partners MSH6 or $\mathrm{MSH} 3$, interacted with NPM-ALK. ${ }^{9}$ In view of the importance of MSH2 in MMR, we hypothesized that NPM-ALK may disrupt MMR function. Regarding the MMR function, it is documented that several MMR proteins are required to work in concert to fully exert this biological property (reviewed by $\mathrm{Li}^{10}$ ). MMR proteins are highly and ubiquitously expressed, ${ }^{11}$ and evidence suggests that the correct ratio between these proteins is key to their function. ${ }^{12-18}$ The MMR protein heterodimer MSH2.MSH6 (also known as MutS $\alpha$ ) detects both single base mismatches and small insertion-deletion loops (one or two nucleotides), whereas the MSH2.MSH3 heterodimer (also known as MutS $\beta$ ) detects only insertion-deletion loops (two to 14 nucleotides). ${ }^{10}$ Normally, MSH2.MSH6 is 10 -fold more abundant than MSH2.MSH3. ${ }^{13}$ Once a MutS heterodimer is bound to the site of DNA error, a second MMR heterodimer consisting of MutL orthologs (eg, MLH1.PMS2) is recruited, followed by the recruitment of additional proteins that mediate the removal of the erroneous DNA bases, using the unaffected strand as a template to resynthesize the DNA. ${ }^{10}$ The formation of heterodimers stabilizes these MMR proteins. Cells lacking MSH2 can form neither MSH2.MSH6 nor $\mathrm{MSH} 2 \cdot \mathrm{MSH} 3$ and are completely deficient in MMR function, whereas cells lacking one of MSH6 or MSH3 retain $\mathrm{MSH} 2 \mathrm{MSH} 3$ or $\mathrm{MSH} \cdot \mathrm{MSH} 6$, respectively, and hence some residual error correction. ${ }^{19-25}$ The MSH2.MSH6 heterodimer performs the majority of mutation repair, ${ }^{26}$ an observation that is supported by tumor latency studies using MMR-null mice. ${ }^{20,21,25,27}$ By 6 and 11 months, $50 \%$ of Msh2 $^{-1-}$ and $\mathrm{Msh6}^{-1-}$ mice succumb to MMR-related tumors, whereas $\mathrm{Msh}^{-1-}$ survival is at least 18 months and tumor incidence is low. ${ }^{27}$

The importance of MMR function to tumor suppression in humans has been characterized most extensively in Lynch syndrome, an early-onset cancer syndrome affecting a heterogeneous group of tissues (eg, colon, endometrium, urothelium; OMIM\#120435, http://www.ncbi.n/m. nih.gov/omim). In addition, acquired inactivation of MMR contributes to a proportion of sporadic cancers. ${ }^{28}$ The congenital loss of MMR function through the inheritance of two mutated copies of a gene encoding a MMR protein, including $\mathrm{MSH} 2$, is associated with the development of lymphoid cancer presenting in childhood. ${ }^{29}$ In their recent review of the literature and analysis of microsatellite instability (MSI) in non-Hodgkin lymphoma, Miyashita et al concluded that MSI was not infrequent in lymphoma and was associated with poor clinical outcomes and resistance to chemotherapy. ${ }^{30}$ These studies suggest that MMR deficiency is pathogenetically important in human lymphoid malignancies. With this background, we sought to determine whether the scope of NPM-ALK oncogenic- ity includes interference with MSH2 biology and MMR function.

\section{Materials and Methods}

\section{Cells and Gene Transfection}

Karpas 299 and SUP-M2 are ALK ${ }^{+}$ALCL cell lines and were maintained in RPMI with $10 \%$ fetal bovine serum (FBS; Sigma-Aldrich, Oakville, ON, Canada). The purchased Tet-on HEK293 Advanced cells (Clontech, Mountain View, CA) carried the $\mathrm{rtTA}^{\mathrm{S}}-\mathrm{M} 2$ (Tet-On ${ }^{\circledR} \mathrm{Ad}$ vanced) transactivator under stable transfection, which was maintained via $100 \mu \mathrm{g} / \mathrm{mL}$ G418 in the medium. NPM-ALK CDNA was inserted into the PTRE-TIGHT vector (Clontech), linearized, and introduced into the Tet-on HEK293 cells via stable transfection in conjunction with a linear hygromycin marker. The resulting clonal Tet-on HEK293 Advanced cells carrying PTRE-TIGHT/NPM-ALK were maintained in Dulbecco's modified Eagle's medium supplemented with 10\% Tet-System Approved FBS (Clontech), $100 \mu \mathrm{g} / \mathrm{mL} \mathrm{G} 418$ and $50 \mu \mathrm{g} / \mathrm{mL}$ hyrogomycin B (Clontech) and termed "Tet-on HEK293/NPM-ALK" cells throughout this article. All cells were grown at $37^{\circ} \mathrm{C}$ in $5 \% \mathrm{CO}_{2}$. In some experiments, standard HEK293 cells were transiently transfected with various NPM-ALK expression vectors using Lipofectamine 2000 (Invitrogen, Burlington, ON, Canada) in accordance with the manufacturer's suggested protocol. In the case of vectors that result in a His-biotin (HB) tag, the culture media was supplemented with $4 \mu \mathrm{mol} / \mathrm{L}$ biotin to improve the biotinylation efficiency of HB-tagged proteins.

\section{NPM-ALK Expression Vectors}

His-biotin tagged (HBT) NPM-ALK was constructed as described previously'; HBT consists of a RGS-hexahistidine $(\mathrm{H})$ tag and a bacterially derived biotinylation $(\mathrm{B})$ signal peptide. HB/NPM-ALK expresses functional NPMALK at levels similar to those found in $\mathrm{ALK}^{+} \mathrm{ALCL}$ cell lines. ${ }^{9}$ Site-directed mutagenesis $(\mathrm{Y} \rightarrow \mathrm{F})$ was used to change one or more of the three tyrosine residues of NPM-ALK in kinase activation loop (including Y338, Y342, and Y343) to phenylalanine (F). ${ }^{31}$ Specifically, mutation of all these three tyrosine residues (termed FFF in figures) resulted in a loss of i) NPM-ALK phosphorylation, ii) phosphorylation of many known NPM-ALK downstream targets, and iii) NPM-ALK-induced growth advantage on clonogenic assay. ${ }^{31}$

\section{Nuclear and Cytoplasmic Fractionation}

Nuclear and cytoplasmic proteins were isolated using the Pierce NE-PER kit (Fisher Scientific Canada, Ottawa, ON, Canada). $\beta$-Tubulin and lamin $\mathrm{A} / \mathrm{C}$ were used as cytoplasmic and nuclear markers, respectively, during sodium docedyl sulfate-polyacrylamide gel electrophoresis (SDS-PAGE) analysis. 
Table 1. Primer Sequences Used in Microsatellite Analysis

\begin{tabular}{|c|c|c|}
\hline Locus & Primer sequence & Reference \\
\hline \multicolumn{3}{|c|}{ Mononucleotide microsatellites } \\
\hline Forward primer & 5'-TGACTACTTTTGACTTCAGCC-3' & 62 \\
\hline Reverse primer & 5'-GTTTCTTAACCATTCAACATTTTTAACCC-3' & 62 \\
\hline \multicolumn{3}{|c|}{ (2) } \\
\hline Forward primer & 5'-TCGCCTCCAAGAATGTTAGT-3' & 62 \\
\hline Reverse primer & 5'-GTTTCTTTGGCTCTAAAATGCTCTGTTCT-3' & Designed using Primer3 \\
\hline \multicolumn{3}{|c|}{ e } \\
\hline Forward primer & $5^{\prime}$-CCTAGAAACCTTTATCCСТGCTT-3' & 63 \\
\hline \multirow{2}{*}{\multicolumn{3}{|c|}{ 2.GITILTIAAGLTGAATLGIGLCALTG-3 }} \\
\hline & & \\
\hline Forward primer & $5^{\prime}$-GAGTCGCTGGCACAGTTCTA-3' & 53 \\
\hline Reverse primer & 5'-GTTTCTTGCATTCACACTTTCTGGTCA-3' & Designed using Primer3 \\
\hline \multicolumn{3}{|c|}{ (2) } \\
\hline Forward primer & 5'-GCTGAATTTTACCTCCTGAC-3' & 53 \\
\hline Reverse primer & 5' -GTTTCTTCATTCCAACCTGGGTA-3' & Designed using Primer3 \\
\hline \multicolumn{3}{|c|}{ 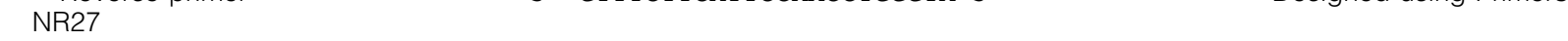 } \\
\hline Forward primer & $5^{\prime}$-AACCATGCTTGCAAACCACT-3' & 53 \\
\hline Reverse primer & $5^{\prime}$-GTTTCTTTCAACAGCAGAGACCTTGTCA-3' & Designed using Primer3 \\
\hline \multicolumn{3}{|c|}{ Dinucleotide microsatellites } \\
\hline \multicolumn{3}{|l|}{ D2S123 } \\
\hline Forward primer & $5^{\prime}$-GCCAGAGAAATTAGACACAGTC-3' & 62 \\
\hline Reverse primer & 5'-GTTTCTTCTGACTTGGATACCATCTATCTA-3' & 62 \\
\hline \multicolumn{3}{|c|}{ a } \\
\hline Forward primer & $5^{\prime}$-TACTCACTCTAGTGATAAATCGG-3' & 62 \\
\hline Reverse primer & 5'-GTTTCTTTTCAGGGAATTGAGAGTTACAG-3' & 62 \\
\hline \multicolumn{3}{|l|}{ D17S250 } \\
\hline Forward primer & 5'-AATACACAATAAAAATATGTGTGTG-3' & 62 \\
\hline Reverse primer & 5'-GTTTCTTTTACAGGCATGAGCCACT-3' & Designed using Primer3 \\
\hline
\end{tabular}

Underlined markers are components of the National Cancer Institute recommended panel of MSI markers for Lynch testing. Primers unique to the laboratory of the authors of the current work were designed using Primer3 (Ref. 61).

\section{Immunoprecipitation and His-Based Protein Purification}

Unless noted otherwise, co-immunoprecipitations (co-IPPs) were performed using $2 \mathrm{mg}$ cell lysate proteins harvested in Cellytic M Lysis Buffer supplemented with protease and phosphatase inhibitors (Sigma-Aldrich). Cell lysate was precleared using $30 \mu \mathrm{L}$ of a $33 \%$ slurry of protein $\mathrm{A} / \mathrm{G}$ agarose beads (EMD Biosciences, Gibbstown, NJ) for 2 hours. For each co-IPP, the pre-cleared lysates was first incubated with $10 \mu \mathrm{g}$ monoclonal antibody overnight, and then $50 \mu \mathrm{L}$ $\mathrm{A} / \mathrm{G}$ agarose beads (packed volume of washed bead) were added and the resulting mixture was incubated overnight. The bead/antibody complexes were washed twice with PBS and then twice with lysis buffer. All liquid was removed and the proteins removed from the beads with loading buffer under standard denaturing conditions. For IPPs the final steps included washing in RIPA buffer. For the purification of NPM-ALK (mutant or native) tagged with HBT, NPM-ALK was purified on streptavidin-coated beads as previously published. ${ }^{9}$ For the co-IPP of MSH2-containing MMR heterodimers, $1.0 \mathrm{mg}$ lysate/IPP was used. Purified proteins resulting from IPP, co-IPP, and streptavidin purification, as well as regular cell lysates, were separated by electrophoresis using $8 \%$ or gradient Pierce Precise Protein Gels (Fisher Scientific Canada). Antibodies used include: anti-MSH2 (clones NA27, NA26, EMD Biosciences), anti-MSH6 (BD Biosciences, Mississauga, ON, Canada), anti-MSH3 (Santa Cruz Biotechnologies, Santa
Cruz, CA), and anti-phospho-tyrosine (mAb P-Tyr-102, Cell Signaling, Danvers, MA).

\section{Detection of Microsatellite Instability in ALK ${ }^{+}$ALCL Tumors}

Six quasi-monomorphic microsatellites (Table 1) were amplified using the Qiagen Multiplex PCR kit. Two of the markers, BAT25 and BAT26, are components of the panel of five markers recommended for Lynch testing ${ }^{32}$; because the remaining three markers in the recommended panel require a patient-matched nontumor DNA sample, they were not used in this study. Instead, we chose four additional monomorphic markers that are mono-nucleotide repeats proved to be informative for the detection of microsatellite instability (MSI) in Lynch associated with the loss of MSH6. ${ }^{33-35}$ DNA samples were isolated from eight normal donors and nine $\mathrm{ALK}^{+} \mathrm{ALCL}$ tumors. Tumor DNA was isolated from paraffin curls using the Qiagen Blood and Tissue Kit (Qiagen, Mississagua, ON, Canada). The use of the human samples has been approved by our Institutional Ethics Review Board. Resulting PCR products were analyzed on an $A B I 3130 x \mid$ Genetic Analyzer (Applied Biosystems, Foster City, CA). Normal DNA samples were used to define the normal profile for the six microsatellites, and the microsatellite profiles of the eight tumors were compared with those of the normal samples. As two of the eight normal samples demonstrated shifts at one microsatellite marker each, only the 
tumor samples that demonstrated shift at two or more microsatellite markers were considered to be positive for MSI.

\section{Immunohistochemistry}

$\mathrm{ALK}^{+} \mathrm{ALCL}$ tumors $(n=5)$ that were formalin fixed and paraffin embedded were used for this study. All cases were retrieved from the file at the Department of Laboratory Medicine and Pathology, Cross Cancer Institute. The diagnosis of these cases was based on the criteria established by the World Health Organization classification scheme, and all cases were confirmed to express ALK by immunohistochemistry. Immunohistochemical detection of $\mathrm{MSH} 2, \mathrm{MSH} 3$, and $\mathrm{MSH} 6$ was performed using standard techniques. Briefly, formalin-fixed, paraffin-embedded tissue sections of $4-\mu \mathrm{m}$ thickness were deparaffinized and hydrated. Antigen retrieval was performed using microwave-treated citrate buffer ( $\mathrm{pH} \mathrm{6.0)} \mathrm{for} 20$ minutes. After antigen retrieval, tissue sections were incubated with $10 \%$ hydrogen peroxide $\left(\mathrm{H}_{2} \mathrm{O}_{2}\right)$ and methanol for 10 minutes to block endogenous peroxidase activity, followed by washing in running tap water for 5 minutes. Subsequently, the sections were incubated overnight at $4^{\circ} \mathrm{C}$ with a mouse monoclonal anti-MSH2 antibody (1:30, Novocastra, Newcastle, UK), a rabbit polyclonal antibody reactive with anti-MSH3 (1:50 dilution, Santa Cruz Biotechnology), or a mouse monoclonal anti-MSH6 antibody (1:50 dilution, BD Transduction Laboratories). Immunostaining was visualized with a labeled streptavidin-biotin method using (3, 3'-diaminobenzidine/ $\mathrm{H}_{2} \mathrm{O}_{2}$ ) DAB as a chromogen (Dako, Mississauga, ON, Canada). Hematoxylin was used as a counter stain.

\section{MMR Functional Assay Using 6TG}

The sensitivity of cells to 6-thioguanine (6TG) was tested in 96-well format, and the resulting cell viability was assayed using the WST-1 cell proliferation reagent (Clontech) with the absorbance read using a $\mu$ Quant 96-well plate reader and the associated KC4 software (BioTek, Winooski, VT). Each sample was performed in quadruplicate with appropriate controls, and the assay repeated three times. In the case of transient transfection, HEK293 cells were harvested and mixed with the plasmid/Attractgene transfection reagent solution as per the FastForward protocol (Qiagen), and immediately aliquoted into the 96-well plate. Tet-on HEK293/ NPM-ALK cells were plated at 4000 cells per well, and the appropriate wells were supplemented with doxycycline/medium or medium alone after 24 hours. After another 24 hours of incubation with doxycycline, the medium was removed and replaced with fresh medium containing doxycycline and 6TG as required.

\section{MMR Functional Assay: Reporter Plasmid for Insertion-Deletion Correction}

Tet-on HEK293/NPM-ALK cells were seeded in 24-well plates and transfected with the pCAR-OF vector (Add-
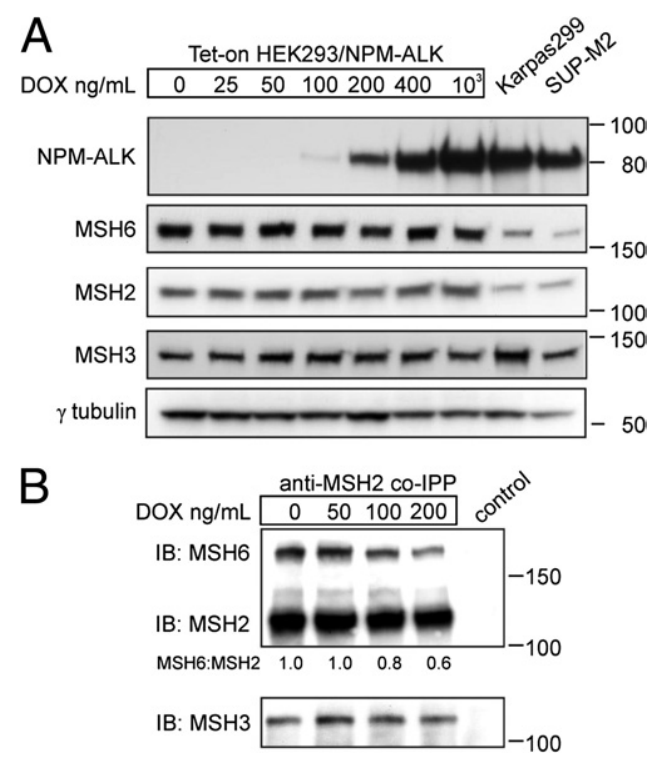

Figure 1. NPM-ALK interferes with MSH2.MSH6. A: Addition of increasing doses of doxycycline to the Tet-on HEK-293/NPM-ALK cells induced a dosedependent increment of the NPM-ALK level. No substantial changes in the total proteins levels of MSH2, MSH3, and MSH6 were noted. $\gamma$-Tubulin served as the protein loading control. Lysates from two ALK ${ }^{+}$ALCL cell lines, Karpas 299 and SUP-M2, were included for comparison. B: Tet-on HEK293/NPMALK cells were cultured in increasing concentrations of doxycycline (ie, increased NPM-ALK expression). Co-IPP was performed with a specific antiMSH2 antibody, and the resulting immunoblot was probed to assess the levels of co-immunoprecipitated MSH6 and MSH3 relative to MSH2. A control co-IPP with no added antibody was included to account for nonspecific binding. Densitometry values for MSH6:MSH2 are shown. Although the amount of MSH6 bound to MSH2 decreased with increasing levels of doxycycline (ie, NPM-ALK), the MSH3:MSH2 ratios remained constant.

gene plasmid 16627, Cambridge, MA) created in the laboratory of Dr. Bert Vogelstein (Johns Hopkins Kimmel Cancer Center). ${ }^{36}$ The pCAR-OF vector contains a $(\mathrm{CA})_{29}$ repeat at the $5^{\prime}$-end of the coding region that places the $\beta$-galactosidase cDNA out of frame; strandslippage resulting from MMR suppression is manifested by the acquisition of $\beta$-galactosidase expression and resultant activity. Seventy-two hours after transfection, cells were harvested and counted. The activity of $\beta$-galactosidase was analyzed using the $\beta$-Galactosidase Enzyme Assay System (Promega, Madison, WI) as per the manufacturer's instructions; the $\beta$-galactosidase activity was reported relative to the total cell number.

\section{Results}

\section{NPM-ALK Interferes with MSH2·MSH6 Heterodimerization}

Using liquid chromatography-mass spectrometry and co-immunoprecipitation (co-IPP) experiments, we previously found evidence that $\mathrm{MSH} 2$ is a binding partner of NPM-ALK. ${ }^{9}$ Interestingly, we did not detect MSH6 or MSH3 in the NPM-ALK-interacting complex by mass spectrometry. ${ }^{9}$ In the present study, using co-IPP, we also found no evidence of binding between MSH6 and NPM-ALK in ALK+ ALCL cell lines (data not shown) and HEK293 cells transfected with NPM-ALK (see below). 


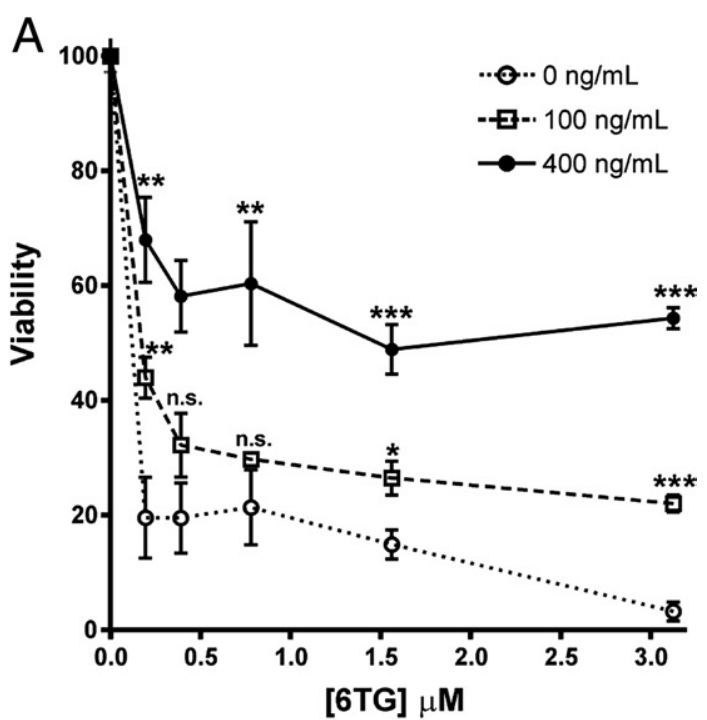

B

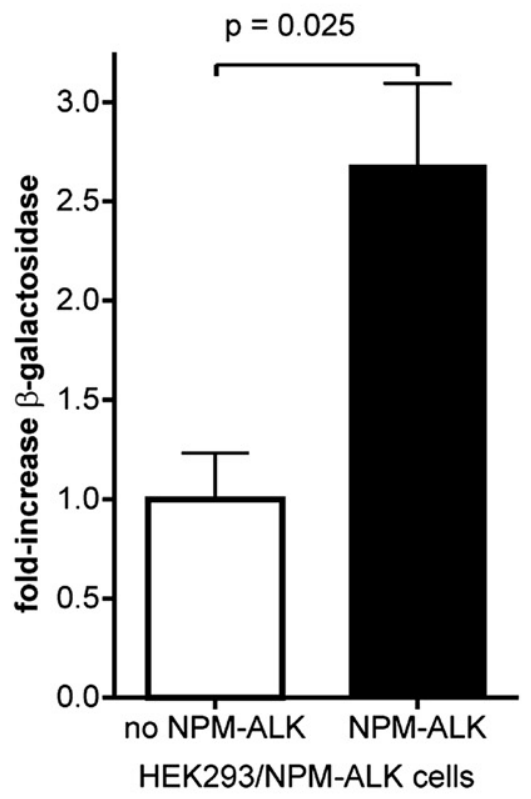

\section{C $\quad \mathrm{NR}-27(\mathbf{A})_{27}$}

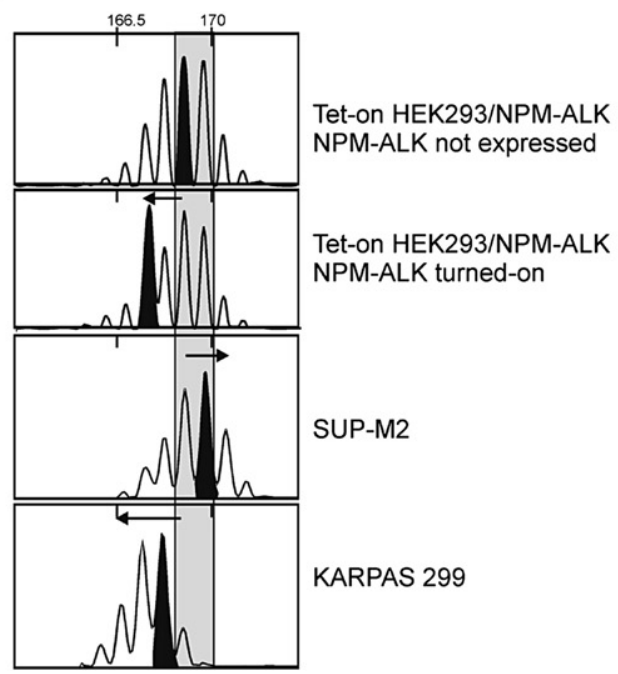

These findings led us to hypothesize that NPM-ALK may interfere with the normal dimerization between $\mathrm{MSH} 2$ and MSH6. In support of this hypothesis, using the Tet-on HEK-293/NPM-ALK cells and co-IPP with an MSH2-specific antibody, we found that the ratio of MSH6 bound to MSH2 decreased as the NPM-ALK levels were gradually increased in a dose-dependent manner (Figure 1). Using the same experimental model, we found a dose-dependent increase in the MSH2.NPM-ALK binding as the NPM-ALK levels were gradually increased (see Supplemental Figure S1 at http://ajp.amjpathol.org). These findings support the model in which NPM-ALK sequestrates MSH2 away from MSH6. This model is further supported by our finding that siRNA knock-down of NPM-ALK in $\mathrm{ALK}^{+} \mathrm{ALCL}$ cells resulted in an increase in the MSH2.MSH6 interaction in co-IPP experiments (see Supplemental Figure S2 at http://ajp.amjpathol.org).

\section{NPM-ALK Suppresses DNA Mismatch Repair Function}

In view of the importance of the MSH2.MSH6 interaction in the context of MMR, our finding that NPM-ALK interferes with this interaction led us to hypothesize that NPMALK suppresses MMR function. This hypothesis was supported by the results of two different in vitro assays described below.

\section{TG Assay}

The 6TG assay, a widely accepted test for evaluating MMR function, ${ }^{37,38}$ was used to assess the impact of NPM-ALK on MMR function. As described in the literature, the incorporation of 6TG metabolites into DNA is

Figure 2. NPM-ALK suppresses MMR function in vitro. A: Tet-on HEK-293/ NPM-ALK were grown in three specified doxycycline concentrations $(0,100$ $\mathrm{ng} / \mathrm{mL}$, and $400 \mathrm{ng} / \mathrm{mL}$ ) for 24 hours, and then 6TG was added for an additional 48 hours. The WST-1 assay was used to compare relative cell viability/proliferation, and the resulting colormetric response was measured with a $\mu$ Quant BioTeck plate reader. Each experiment was plated in quadruplicate. Figure $2 \mathrm{~A}$ shows a representative experiment. The results showed that doxycycline-induced expression of NPM-ALK in the Tet-on HEK293/ NPM-ALK cells resulted in a significant increase in cell viability. Data are represented as mean \pm SEM. Stars denote statistical difference between 0 $\mathrm{ng} / \mathrm{mL}$ doxycycline and doxycycline-induced cells using one-way analysis of variance and the Newman-Keuls multiple comparison test (GraphPad Prism); ${ }^{*} P<0.05,{ }^{* *} P<0.01$, and ${ }^{* * *} P<0.001$. n.s. $=$ not significant. Comparing the $100-$ and $400-\mathrm{ng} / \mathrm{mL}$ data, differences were statistically different $(P<0.05)$ at all doses, with the two highest reaching greater significance $(3.125 \mu \mathrm{mol} / \mathrm{L}$, $P<0.001 ; 1.56 \mu \mathrm{mol} / \mathrm{L}, P<0.01)$. B: Tet-on HEK293/NPM-ALK cells were transiently transfected with the pCAR-OF vector, which carries CDNA encoding $\beta$-galactosidase placed out of frame by a $(\mathrm{CA})_{29}$ repeat. Four hours after transfection, the medium was supplemented by either $400 \mathrm{ng} / \mathrm{mL}$ doxycycline (with NPM-ALK expression) or $0 \mathrm{ng} / \mathrm{mL}$ doxycycline (no NPM-ALK). Seventy-two hours after transfection, the cell lysates were assayed for $\beta$-galactosidase activity, an indication of suppressed MMR function. Cells with NPM-ALK expression showed a significantly higher level of $\beta$-galactosidase activity compared with cells with no expression of NPM-ALK. C: Tet-on HEK293/NPM-ALK cells were subjected to clonal expansion for 10 days in the presence $(1000 \mathrm{ng} / \mathrm{mL}$ doxycycline at the initial concentration) or absence $(0 \mathrm{ng} / \mathrm{mL}$ doxycycline $)$ of NPM-ALK expression. DNA was harvested and MSI tested at both mono- and di-nucleotide microsatellites. MSI was detected at NR-27, which is also affected in ALK ${ }^{+}$ALCL cell lines. Shaded area represents the location of the predominant peaks in MMR-proficient cells. 
not in itself cytotoxic, but the resulting aberrant base requires MMR processing to exert its cytotoxic effects. ${ }^{37}$ Thus, in cells with normal MMR function, 6TG is cytotoxic; in the absence of MMR, 6TG is not cytotoxic. ${ }^{38}$ As shown in Figure 2A, doxycycline-induced expression of NPM-ALK in the Tet-on HEK293/NPMALK cells resulted in a significantly high number of viable cells than without NPM-ALK expression. This increased viability was significant at a relatively lowlevel of NPM-ALK expression (100 $\mathrm{ng} / \mathrm{mL}$ doxycycline) and the difference was more pronounced at relatively high-level NPM-ALK expression (400 ng/mL doxycycline), indicating a dose-dependent relationship between NPM-ALK levels and MMR suppression.

\section{Reporter Assay for MMR Function}

MMR function after NPM-ALK expression also was tested using a previously described reporter plasmid containing the cDNA encoding $\beta$-galactosidase placed out of frame by a $(C A)_{29}$ repeat. ${ }^{36}$ As described in Materials and Methods, strand slippage resulting from MMR suppression is manifested by the acquisition of $\beta$-galactosidase expression and its resultant activity. As shown in Figure 2B, induced expression of NPM-ALK in Tet-on HEK293/NPM-ALK cells resulted in a significant increase of $\beta$-galactosidase activity, as compared with cells with no added doxycycline $(P=0.025)$, and this finding further supports that MMR function was suppressed by NPM-ALK.

\section{Interference of NPM-ALK·MSH2 Binding Restores MMR Function}

Thus far, our data have supported a model in which NPM-ALK suppresses MMR function via sequestrating $\mathrm{MSH} 2$ away from MSH6. This model predicts that abrogation of the NPM-ALK.MSH2 binding may restore the normal interaction between MSH2 and MSH6 and thus, the MMR function. Because NPM-ALK is known to interact with other proteins primarily through its phosphorylated tyrosine residues, we hypothesized that mutation (ie, replaced by phenylalanine) of the one of the tyrosine residues involved in phosphorylation may decrease the NPM-ALK.MSH2 binding. Of the eight tyrosine residues that are outside the kinase activation loop of ALK and are known to be involved in phosphorylation, ${ }^{31,39}$ only NPM-ALK ${ }^{Y 191}$ showed an appreciable (60\% reduction by densitometry) decrease in the NPMALK.MSH2 interaction (Figure 3A). NPM-ALK ${ }^{\mathrm{Y} 191}$ has not been identified as contributing to any previously reported NPM-ALK activated signaling pathway, thus minimizing the contribution of off-target effects, and the Y191F mutation does not result in reduced NPMALK conferred growth advantage. ${ }^{31}$ Compared with native NPM-ALK, transient transfection of the NPMALK $^{\mathrm{Y} 191 \mathrm{~F}}$ mutant conferred a significantly lower suppressive effect on MMR function (Figure 3B), demonstrating that the binding between MSH2 and NPM-ALK is essential for mediating NPM-ALK-induced MMR
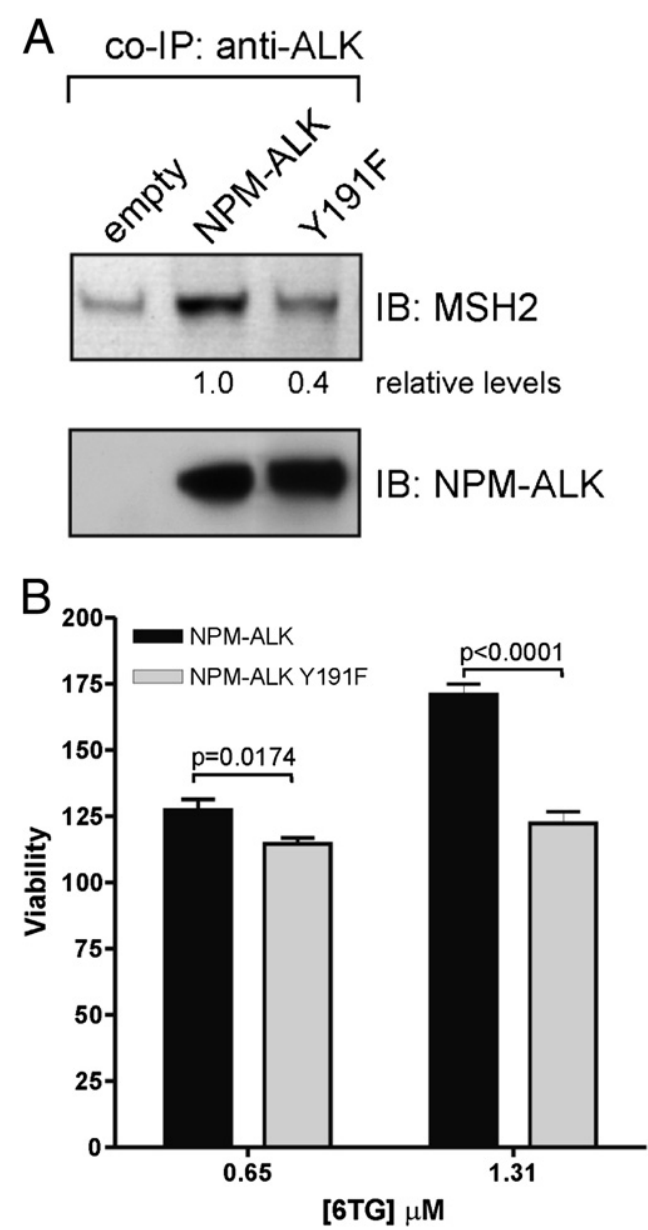

Figure 3. Disruption of NPM-ALK'MSH2 binding restores MMR function. A In this experiment, HEK293 cells were transiently transfected with empty vector, $N P M-A L K$, or NPM-ALK ${ }^{Y 191 F}$. NPM-ALK was precipitated from the resulting lysates under CO-IPP conditions, and the resulting immunoblot was probed for MSH2 as well as for NPM-ALK. A relatively low level of nonspecific binding of $\mathrm{MSH} 2$ to the $\mathrm{A} / \mathrm{G}$ coated agarose beads was observed. Nevertheless, when taking this nonspecific binding into account, we found that the Y191F mutation resulted in a 60\% decrease in NPM-ALK.MSH2 binding. Triplicate experiments were performed and results from a representative experiment were shown. B: HEK293 cells were transiently transfected with empty vector, NPM-ALK, or NPM-ALK Y191F. 6TG sensitivity was assayed as described for Figure 2A. Viability was expressed as a percentage relative to the empty vector, which was set as $100 \%$. The Y191F mutant resulted in a significantly lower cell viability than NPM-ALK did, at both 6TG dosages $(0.65$ and $1.31 \mu \mathrm{mol} / \mathrm{L}$ ).

suppression. The observed decrease in cell viability (thus, a partial restoration in MMR function) on mutation of NPM-ALK at tyrosine 191 (Figure 3B) is in agreement with the $60 \%$ reduction in $\mathrm{MSH} 2$-binding observed for NPM-ALK ${ }^{\text {191F }}$ (Figure $3 \mathrm{~A}$ ). Regarding the question as to how the mutation of $Y 191$ results in a lesser degree of MMR suppression, we considered the possibility that NPM-ALK ${ }^{\text {191F }}$ may not interfere with the MSH2.MSH6 interaction as effectively as native NPM-ALK does. To test this possibility, we performed co-IPP experiments using Tet-on HEK293/NPM-ALK cells transiently transfected with NPM-ALK or NPM-ALK ${ }^{\text {Y191F. In the absence }}$ of doxycycline, $\mathrm{MSH} 2$ pulled down substantially more MSH6 with the transient expression of NPM-ALK ${ }^{\text {Y191F }}$ as compared with NPM-ALK (see Supplemental Figure S3 at http://ajp.amjpathol.org). Furthermore, in the 

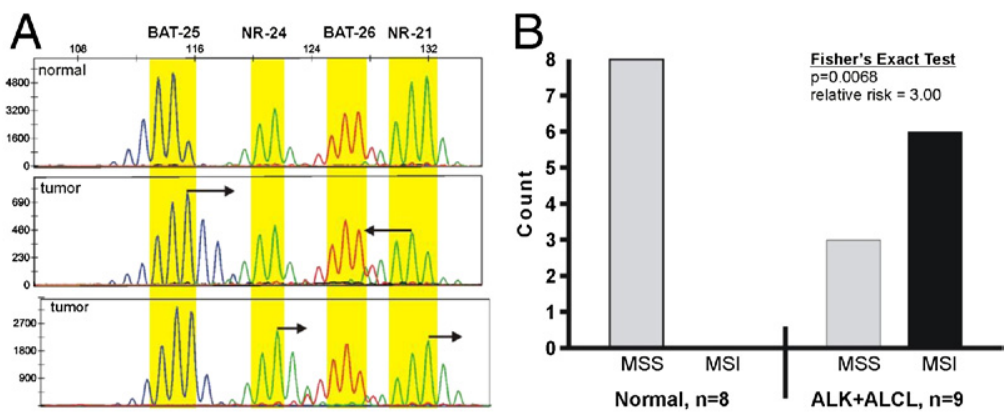

\begin{abstract}
Figure 4. Evidence of MMR dysfunction in $\mathrm{ALK}^{+} \mathrm{ALCL}$ tumor samples. A: Six quasi-monomorphic microsatellites were amplified using the QIAGEN Multiplex PCR kit and previously reported primers (Table 1). Eight DNA samples were isolated from normal donors, and nine DNA samples from nine $\mathrm{ALK}^{+}$ALCL tumors were isolated from paraffin curls using the Qiagen Blood and Tissue Kit (Qiagen). Resulting PCR samples were analyzed on the ABI 3130xl Genetic Analyzer (Applied Biosystems). Compared with nonmatched normal DNA the tumor samples displayed a significantly increased frequency of MSI, with a significant increase in relative risk Yellow depicts the range of the normal DNA traces, as determined by analysis of eight normal individuals. Arrows indicate shifts of the predominant peaks in the two representative $\mathrm{ALK}^{+}$ALCL tumors. B: Summary of the MSI analysis of normal samples $(n=8)$ and $\mathrm{ALK}^{+}$ALCL tumors $(n=9)$. The frequency of MSI is significantly higher in ALK+ALCL tumors than normal samples $(P=0.0068$, Fisher exact test $)$ MSS $=$ microsatellite stable. C: MSH2 protein was found largely in the germinal centers (arrow) in a reactive tonsil (low magnification). D: MSH2 was found localized to the nuclei (arrows) of benign lymphoid cells (high magnification of $\mathbf{C}$ ). $\mathbf{E}$ and $\mathbf{F}$ : Two high-magnification views of $\mathrm{ALK}^{+} \mathrm{ALCL}$ cells, many of which have intense cytoplasmic MSH2 staining (red arrows). The nuclei of the neoplastic cells were highlighted by yellow arrows. The benign lymphocytes had predominantly nuclear staining (green arrows). $\mathbf{G}$ and $\mathbf{H}$ : Cytoplasmic staining of MSH6 and MSH3 were also readily detectable
\end{abstract} in $\mathrm{ALK}^{+}$ALCL cells.

presence of doxycycline, MSH2 also pulled down more MSH6 in the transient transfection of NPM-ALK ${ }^{Y 191 F}$ as compared with NPM-ALK.

\section{Evidence of MMR Dysfunction in $A L K^{+} A L C L$ Tumors from Patients}

We then asked whether $\mathrm{ALK}^{+} \mathrm{ALCL}$ patient tumor samples display evidence of MMR dysfunction. As described above, MMR function includes the repair of insertiondeletion-loops in areas of highly repetitive DNA sequence (ie, microsatellites); expansion/contraction of microsatellites, commonly referred to microsatellite instability (MSI), is a hallmark of MMR deficiency. We looked for MSI in a panel of $9 \mathrm{ALK}^{+} \mathrm{ALCL}$ tumor samples and 8 normal DNA samples (nonpatient matched), and the results are illustrated in Figure 4A. We found a significant increase in the frequency of $\mathrm{MSI}$ in $\mathrm{ALK}^{+} \mathrm{ALCL}$ tumors (six of nine) as compared with the normal DNA samples (none of eight) $(P=0.007$, relative risk $=3.00$; illustrated in Figure 4B). Karpas 299 and SUP-M2, two ALK ${ }^{+}$ALCL cell lines, also displayed evidence of MSI (Figure 2C).

$\mathrm{MSH} 2$ is predominantly localized to the nucleus in normal cells, ${ }^{40,41}$ and nuclear MMR protein levels have been reported to be increased in rapidly proliferating nontumor cells. ${ }^{42,43}$ Using immunohistochemistry and paraffin-embedded $\mathrm{ALK}^{+} \mathrm{ALCL}$ tumors, we examined whether there is any evidence of abnormal subcellular localization of $\mathrm{MSH} 2$ in $\mathrm{ALK}^{+} \mathrm{ALCL}$ cells. As shown in Figure 4, A and B, lymphocytes in benign reactive tonsils showed a predominantly nuclear staining pattern. In contrast, in large $\mathrm{ALK}^{+} \mathrm{ALCL}$ cells, we readily identified cytoplasmic MSH2 staining (Figure 4, C and D). In these tumorous samples, one can also appreciate that the small benign lymphocytes, which are often found admixed with the large lymphomatous cells, displayed the expected, predominantly MSH2 nuclear staining pattern. We performed similar studies for MSH3 and MSH6. As shown in Figure 4, G and $\mathrm{H}$, cytoplasmic staining of MSH3 and MSH6 was readily detectable in $\mathrm{ALK}^{+} \mathrm{ALCL}$ cells. These findings provide further evidence to support that the biochemistry/function of $\mathrm{MSH}$ proteins is deregulated in these cells.

\section{NPM-ALK Impedes the DNA Adduct-Induced Relocalization of MSH2}

The exposure of cells to DNA damaging agents has been previously shown to induce a movement of $\mathrm{MSH} 2 \cdot \mathrm{MSH} 6$ heterodimer out of the cytoplasm. ${ }^{40,41}$ Considering that NPM-ALK interfered with the MSH2.MSH6 binding and that heterodimerization with $\mathrm{MSH} 6$ is required for effective nuclear import of $\mathrm{MSH} 2,{ }^{44,45}$ we asked whether NPMALK affected this normal MMR response to DNA adducts. Using the Tet-on HEK293/NPM-ALK cells, we performed subcellular fractionation following exposure to 6TG. As shown in Figure 5, in the absence of NPM-ALK (ie, no doxycycline added), we observed an expected reduction in cytoplasmic $\mathrm{MSH} 2$ and $\mathrm{MSH} 6$ levels on exposure to 6TG. In contrast, expression of NPM-ALK abrogated the 6TG-induced reduction in $\mathrm{MSH} 2$ cytoplasmic levels, whereas the normal decrease in the cytoplasmic MSH6 levels was not changed. These changes correlate with our observation that the cytoplasmic MSH2:MSH6 ratios were skewed in the presence of NPM-ALK after 6TG exposure, whereas the ratios remained relatively consistent in the absence of NPM-ALK expression (Figure 5). 


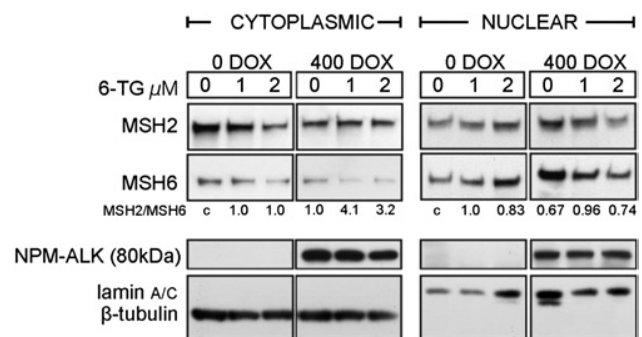

Figure 5. NPM-ALK impedes the DNA adduct-induced re-localization of MSH2. Tet-on Tet-on HEK293/NPM-ALK cells were cultured in $0 \mathrm{ng} / \mathrm{mL}$ doxycycline (no NPM-ALK) or $400 \mathrm{ng} / \mathrm{mL}$ doxycycline (which induced NPMALK expression at a level similar to that in ALK ${ }^{+}$ALCL cell lines) for 24 hours, and then exposed to 6TG for an additional 24 hours. Cells were harvested and the nuclear/cytoplasmic fractionation was performed. The ratio of MSH6 to $\mathrm{MSH} 2$, as determined by densitometry, is indicated; protein levels were normalized to $0 \mathrm{ng} / \mathrm{mL}$ doxycycline and $0 \mu \mathrm{mol} / \mathrm{L}$ 6TG for each fraction (indicated by c, control). The purity of the cytoplasmic and nuclear fractions was confirmed by $\beta$-tubulin and lamin $\mathrm{A} / \mathrm{C}$, respectively. The key finding is that the 6TG-induced reduction in MSH2 cytoplasmic levels was abrogated by the expression of NPM-ALK.

The isolation of $\beta$-tubulin to the cytoplasm and lamin $A / C$ to the nucleus confirmed the purity of the resulting subcellular fractions. These data support a model in which NPM-ALK suppresses MMR function at the level of MSH2-related biochemistry.

\section{NPM-ALK·MSH2 Interaction Is Dependent on Activation Status of NPM-ALK}

The accumulated evidence that NPM-ALK suppressed MMR function through interference with normal MMR biochemistry culminated in the question of whether the NPMALK.MSH2 interaction was dependent on NPM-ALK tyrosine kinase activity. To address this question, we used a panel of NPM-ALK mutants in which one of more of the three tyrosine residues in the kinase activation loop had been replaced by phenylalanine $(Y \rightarrow F$ mutations). ${ }^{31}$ Mutation within the kinase activation loop alters the autophosphorylation of NPM-ALK, and mutation of all three residues (FFF mutant) abrogates NPMALK autophosphorylation and NPM-ALK-induced growth advantage. ${ }^{31}$ As shown in Figure 6A, affinity purification and subsequent immunoblot analysis of various NPM-ALK mutants was performed. In contrast with native NPM-ALK (denoted by YYY), inactive NPMALK (denoted by FFF) failed to demonstrate an interaction with MSH2. With the exception of the YFF mutant, the activation loop mutants displayed reduced levels of MSH2 interaction. The observed variations in NPM-ALK.MSH2 interaction levels were not attributable to the relative levels of NPM-ALK that were purified (Figure 6A) or the overall levels of MSH2 (Figure 6B). It should also be noted that immunoblot analysis of native NPM-ALK (denoted by YYY) revealed a readily detectable interaction with MSH2, but not MSH6 (Figure $6 \mathrm{~A}$ ), which is in keeping with our previous observations. ${ }^{9}$ Therefore, the NPM-ALK·MSH2 interaction was dependent on the activation state of NPM-ALK.

\section{NPM-ALK Expression Induces MSH2 Tyrosine Phosphorylation}

The specific interaction of MSH2 with NPM-ALK raised the question of whether MSH2 may be a direct or indirect target of NPM-ALK tyrosine kinase activity. Comparing MSH2 immunoprecipitated from cells expressing active NPM-ALK (YYY) to cells expressing the inactive NPMALK (FFF), we found tyrosine phosphorylation on $\mathrm{MSH} 2$ greatly increased ( $>5$-fold) in the presence of native NPM-ALK (Figure 6C). The kinase dead NPM-ALKK210R mutant ${ }^{46}$ also demonstrated a failure to tyrosine phosphorylate MSH2 (not shown). Moreover, tyrosine phosphorylation of $\mathrm{MSH} 2$ was also detected in two $\mathrm{ALK}^{+} \mathrm{ALCL}$ cell lines (Figure 6D). Finally, we determine whether NPM-ALK is directly responsible for MSH2 tyrosine phosphorylation in $\mathrm{ALK}^{+} \mathrm{ALCL}$ cells, we knocked down the expression of NPM-ALK in these cells using siRNA. The tyrosine phosphorylation of MSH2 was dramatically decreased after NPM-ALK knock-down (see Supplemental Figure S4 at $h$ ttp://ajp.amjpathol.org).

\section{Discussion}

Recent studies have revealed that the mechanisms by which oncogenic tyrosine kinases mediate tumorigenesis are rather diverse. Directly relevant to the current study, there is accumulating evidence that oncogenic tyrosine
A

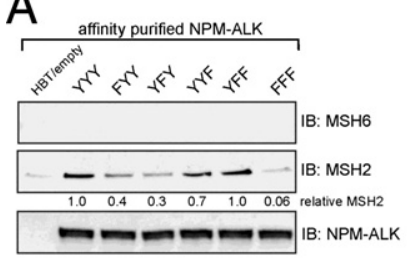

C

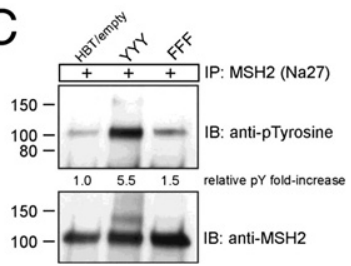

B
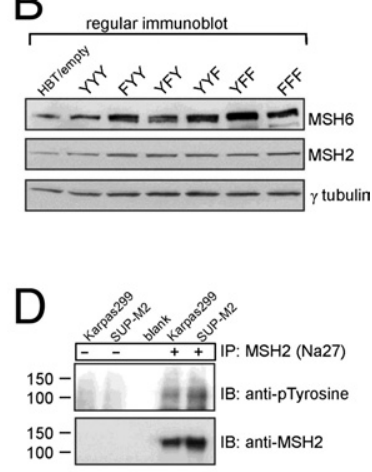

Figure 6. NPM-ALK mediates tyrosine phosphorylation of MSH2. A: NPMALK contains the YxxxYY insulin receptor subfamily motif in its activation loop, and modulation of this loop has been shown to change the autophosphorylation characteristics of NPM-ALK and the oncogenic pressure exerted on the cells. ${ }^{9}$ HEK293 cells were transiently transfected with empty vector, unmodified NPM-ALK (YYY), inactive NPM-ALK (FFF), as well as intermediate $\mathrm{Y} \rightarrow \mathrm{F}$ mutations of the activation loop. Resulting lysates were subjected to purification using on the basis of streptavidin/biotin binding; these NPMALK constructs were HB tagged. The resulting immunoblot was probed for MSH2, MSH6, and NPM-ALK, and the quantification of relative levels of co-precipitated MSH2 is noted. B: Standard immunoblot of the lysates generated as in Figure 1A, showing MSH2 and MSH6 protein levels after NPMALK transfection. C: HEK293 cells were transfected with NPM-ALK, NPM-ALK (FFF), or empty vector. MSH2 was purified from the resulting lysates under IPP conditions, and the resulting immunoblot was probed with anti-phospho-tyrosine antibody. To compare the levels of phospho-MSH2 with total MSH2, the blot was stripped and then probed with anti-MSH2. Densitometry revealed that, relative to the amount of $\mathrm{MSH} 2$ precipitated, that tyrosine phosphorylation of MSH2 is increased 5.5-fold in the presence of NPM-ALK (relative pY-MSH2 values denoted). D: The tyrosine phosphorylation was confirmed in two $\mathrm{ALK}^{+}$ALCL cell lines. 
kinases can redirect cellular processes to favor errorprone DNA repair pathways and to suppress cellular responses to DNA damage/errors. ${ }^{47-51}$ It has been recently shown that expression of the fusion tyrosine kinase $\mathrm{BCR} / \mathrm{ABL}$ reduced the $\mathrm{MMR}$ response to single base mismatches and DNA damage-induced signaling. ${ }^{52}$ Nevertheless, how these oncogenic tyrosine kinases impair MMR function is largely unknown.

One of the key findings of our study is that NPM-ALK indeed suppresses MMR. This conclusion is primarily based on the results of two well-established in vitro assays for MMR functions. First, the impact of NPM-ALK on MMR function was assessed by measuring the cell viability after 6TG treatment. The second assay involves the use of a previously described pCAR-OF vector. Because our conclusion that NPM-ALK suppresses MMR is based on experiments performed on HEK293 cells, an easy-totransfect, human embryonic kidney cell line, we went on to examine $\mathrm{ALK}{ }^{+} \mathrm{ALCL}$ tumors for evidence of MMR dysfunction. We found that the relatively high incidence of $\mathrm{MSI}$, a hallmark of MSI dysfunction, in $\mathrm{ALK}^{+} \mathrm{ALCL}$ patient samples. As NPM-ALK is considered the central pathogenetic factor in this tumor type, we believe that the frequent finding of $\mathrm{MSI}$ in $\mathrm{ALK}^{+} \mathrm{ALCL}$ is in support of our hypothesis. Of note, the choice of microsatellite markers used in this study was somewhat dictated by the intrinsic limitation that all of our study cases were retrospective samples, and normal DNA samples from these same individuals were not available for comparison. With this in mind, we used microsatellites that are considered to be of relatively consistent length (quasi-monomorphic) in normal tissues within the Northern European ancestry. ${ }^{53-55}$ Two of these markers are among the five recommended by the National Cancer Institute. ${ }^{32}$ Moreover, the loci examined in our study have demonstrated increased efficacy for accurately identifying MSI-positive samples in tumor samples in which only the MSH2.MSH6 heterodimer is affected (eg, MSH6-deficient endometrial carcinoma) ${ }^{33}$ It is noteworthy that in tumors associated with the loss of a key MMR protein (eg, Lynch and sporadic), $\mathrm{MSI}$ is not always detectable, likely because of the loci selected for analysis and tumor heterogeneity. We also would like to point out that our finding of a relatively high frequency of $\mathrm{MSI}$ in $\mathrm{ALK}{ }^{+} \mathrm{ALCL}$ differs from that of a previously study in which four $\mathrm{ALK}^{+} \mathrm{ALCL}$ cases were examined and found to have no evidence of MSI at seven dinucleotide repeats. ${ }^{56}$ In this regard, it is known that MSI results are dependent on the markers chosen for analysis, the threshold chosen for instability, and the sensitivity of the assay used. ${ }^{34}$

Although other oncogenic tyrosine kinases, such as $\mathrm{BCR} / \mathrm{ABL}$, have been reported to suppress $\mathrm{MMR},{ }^{52}$ the mechanisms have not been previously studied. We believe that our study has shed light on the possible mechanisms by which oncogenic tyrosine kinases deregulate MMR. Specifically, based on our findings that NPM-ALK binds to MSH2 but not MSH3 or MSH6, we hypothesized that NPM-ALK may suppress MMR by interfering with the MSH2.MSH6 interaction. As mentioned above, MSH2.MSH6 is the predominant MMR protein complex responsible for the detection of postreplicative DNA errors, as well as exogenous and endogenous DNA damage. Our experimental data showed that increasing expression levels of NPM-ALK decreases MSH2.MSH6 binding and promote MSH2·NPM-ALK in a dose-dependent fashion.

To further delineate the mechanism underlying NPMALK-mediated MMR suppression, we generated and used a NPM-ALK mutant, in which the tyrosine 191 was mutated into phenylalanine. As this mutant does not bind to $\mathrm{MSH} 2$ as well as native NPM-ALK does, we were able to use this mutant to address the question of whether the MSH2-NPM-ALK interaction is important for the MMR suppression mediated by NPM-ALK. We found that NPMALK ${ }^{\text {191 }}$ mutant is less efficient in suppressing MMR functions. Furthermore, more MSH6 protein was pulled down with $\mathrm{MSH} 2$ in the presence of NPM-ALK ${ }^{Y 191}$, as compared with native NPM-ALK (see Supplemental Figure S3 at http://ajp.amjpathol.org). Taken together, we believe that our findings support a model in which NPMALK suppresses MMR via sequestrating $\mathrm{MSH} 2$ away from MSH6.

Our finding that the MSH2-NPM-ALK binding is dependent on the activation/phosphorylation status of NPMALK is not surprising, as it is well documented that the interactions between NPM-ALK and its binding partners are largely abrogated when the autophosphorylation of NPM-ALK is reduced or abolished. ${ }^{3}$ Nevertheless, as opposed to the vast majority of the proteins known to interact with NPM-ALK, MSH2 does not contain a SH2 domain. Although we know that the Y191 residue and the overall activation status of NPM-ALK are important in mediating the MSH2.NPM-ALK interaction, the mechanism is not completely understood. We have considered the possibility that the PTB domain present in MSH2 may play a role in mediating a direct physical interaction between NPM-ALK and MSH2. It is also possible that the MSH2.NPM-ALK interaction is indirect and that yet-to-be identified intermediate(s) are involved.

In view of the fact that NPM-ALK is a constitutively active tyrosine kinase, we investigated whether MSH2 can be phosphorylated in the presence of NPM-ALK. In HEK293 cells, we found that enforced expression of NPM-ALK indeed resulted in tyrosine phosphorylation of $\mathrm{MSH}$ 2. Using $\mathrm{ALK}^{+} \mathrm{ALCL}$ cells, we found that $\mathrm{MSH} 2$ is tyrosine phosphorylated. Importantly, we confirmed that NPM-ALK is directly responsible for the tyrosine phosphorylation of MSH2, as siRNA knock-down of NPM-ALK in these cells resulted in a dramatic decrease in the MSH2 tyrosine phosphorylation. The biological significance of MSH2 tyrosine phosphorylation is currently under investigation in our laboratories. Nevertheless, a small number of reports suggest that phosphorylation of MSH2 carries biological importance. For instance, phosphorylation of $\mathrm{MSH} \cdot \mathrm{MSH} 6$ has been shown to alter its DNA binding properties, although tyrosine phosphorylation of $\mathrm{MSH} 2$ was not clearly demonstrated to be involved. ${ }^{41}$ In two other studies, threonine phosphorylation of $\mathrm{MSH} 2$ was found to modulate its stability. ${ }^{57,58}$ We believe that tyrosine phosphorylation of $\mathrm{MSH} 2$ is a highly interesting phenomenon, and studies of its importance are underway in our laboratories. 
Normally, MSH2 is predominantly localized to the nucleus, with lower levels in the cytoplasm, and it is in the cytoplasm that newly translated $\mathrm{MSH} 2$ binds $\mathrm{MSH} 6$ to form MSH2.MSH6. ${ }^{40,41} \mathrm{MSH} 2$ does not contain a clear nuclear localization signal and is largely dependent on MSH6 for co-import into the nucleus. ${ }^{44,45}$ It has previously been shown that there is a movement of the cytoplasmic MSH2 into the nucleus on the induction of DNA damage. ${ }^{40,41}$ In keeping with the concept that NPM-ALK disrupts the MSH2.MSH6 interaction, we found evidence that NPM-ALK also interfere with the MSH2 nuclear translocation on DNA damage, as shown in Figure 5. The observation that MSH6 re-localization was not affected by NPM-ALK is in keeping with the concept that its nuclear translocation is independent of $\mathrm{MSH} 2 .{ }^{45}$ Correlating with these in vitro data, the immunohistochemical studies revealed that $\mathrm{MSH} 2$ was readily detectable in the cytoplasm in $\mathrm{ALK}^{+} \mathrm{ALCL}$ tumor cells, but not the infiltrating small lymphocytes. Although the biological importance of these abnormalities needs to be further defined, we would like to point out that reduced (but not abrogated) levels of MMR proteins have been shown to be sufficient to confer MMR dysfunction. ${ }^{13,18,59,60}$ In other words, it is highly likely that this "cytoplasmic retention" of MSH2 is sufficient to confer MMR dysfunction.

In summary, we have presented evidence that NPMALK suppresses MMR function, and this conclusion echoes our observed high frequency of $\mathrm{MSI}$ in $\mathrm{ALK}^{+} \mathrm{ALCL}$ tumor samples. Our study also has provided evidence that the biology/biochemistry of MSH2 is affected by NPM-ALK, and these alterations may represent some of the underlying mechanisms by which NPM-ALK suppresses MMR function. Further studies are clearly needed to clarify this complicated biological process. The biological importance of tyrosine phosphorylation of MSH2 in the context of oncogenesis also needs to be further delineated.

\section{References}

1. Delsol G, Ralfkiaer E, Stein H, Wright DJE: Anaplastic large cell lymphoma. Pathology and Genetics of Tumors of Haematopoietic and Lymphoid Tissues. Edited by Jaffe E, Harris N, Stein H, Vardiman J. Lyon, France, IARC Press, 2001, pp 230-235

2. Falini B: Anaplastic large cell lymphoma: pathological, molecular and clinical features. Br J Haematol 2001, 114:741-760

3. Amin HM, Lai R: Pathobiology of ALK+ anaplastic large-cell lymphoma. Blood 2007, 110:2259-2267

4. Bischof D, Pulford K, Mason DY, Morris SW: Role of the nucleophosmin (NPM) portion of the non-Hodgkin's lymphoma-associated NPManaplastic lymphoma kinase fusion protein in oncogenesis. Mol Cell Biol 1997, 17:2312-2325

5. Jager R, Hahne J, Jacob A, Egert A, Schenkel J, Wernert N, Schorle $\mathrm{H}$, Wellmann A: Mice transgenic for NPM-ALK develop non-Hodgkin lymphomas. Anticancer Res 2005, 25:3191-3196

6. Wellmann A, Doseeva V, Butscher W, Raffeld M, Fukushima P, StetlerStevenson M, Gardner K: The activated anaplastic lymphoma kinase increases cellular proliferation and oncogene up-regulation in rat 1a fibroblasts. FASEB J 1997, 11:965-972

7. Kuefer MU, Look AT, Pulford K, Behm FG, Pattengale PK, Mason DY, Morris SW: Retrovirus-mediated gene transfer of NPM-ALK causes lymphoid malignancy in mice. Blood 1997, 90:2901-2910

8. Chiarle R, Gong JZ, Guasparri I, Pesci A, Cai J, Liu J, Simmons WJ, Dhall G, Howes J, Piva R, Inghirami G: NPM-ALK transgenic mice spontaneously develop T-cell lymphomas and plasma cell tumors. Blood 2003, 101:1919-1927

9. Wu F, Wang P, Young LC, Lai R, Li L: Proteome-wide identification of novel binding partners to the oncogenic fusion gene protein. NPMALK, using tandem affinity purification and mass spectrometry Am J Pathol 2009, 174:361-370

10. Li GM: Mechanisms and functions of DNA mismatch repair. Cell Res 2008, 18:85-98

11. Rasmussen LJ, Rasmussen M, Lee B, Rasmussen AK, Wilson DM, III, Nielsen FC, Bisgaard HC: Identification of factors interacting with hMSH2 in the fetal liver utilizing the yeast two-hybrid system. In vivo interaction through the $\mathrm{C}$-terminal domains of $\mathrm{hEXO} 1$ and $\mathrm{hMSH} 2$ and comparative expression analysis. Mutat Res 2000, 460:41-52

12. Gibson SL, Narayanan L, Hegan DC, Buermeyer AB, Liskay RM, Glazer PM: Overexpression of the DNA mismatch repair factor PMS2, confers hypermutability and DNA damage tolerance. Cancer Lett 2006

13. Marra G, laccarino I, Lettieri T, Roscilli G, Delmastro P, Jiricny J: Mismatch repair deficiency associated with overexpression of the MSH3 gene. Proc Natl Acad Sci USA 1998, 95:8568-8573

14. Zhang $H$, Richards B, Wilson $T$, Lloyd M, Cranston A, Thorburn A, Fishel R, Meuth M: Apoptosis induced by overexpression of hMSH2 or hMLH1. Cancer Res 1999, 59:3021-3027

15. Young LC, Listgarten J, Trotter MJ, Andrew SE, Tron VA: Evidence that dysregulated DNA mismatch repair characterizes human nonmelanoma skin cancer. Br J Dermatol 2008, 158:59-69

16. Norris AM, Woodruff RD, D'Agostino RB, Jr., Clodfelter JE, Scarpinato KD: Elevated levels of the mismatch repair protein PMS2 are associated with prostate cancer. Prostate 2007, 67:214-225

17. Shcherbakova PV, Kunkel TA: Mutator phenotypes conferred by $\mathrm{MLH} 1$ overexpression and by heterozygosity for mlh1 mutations. Mol Cell Biol 1999, 19:3177-3183

18. Claij $\mathrm{N}$, te Riele $\mathrm{H}$ : Methylation tolerance in mismatch repair proficient cells with low MSH2 protein level. Oncogene 2002, 21:2873-2879

19. Edelmann L, Edelmann W: Loss of DNA mismatch repair function and cancer predisposition in the mouse: animal models for human hereditary nonpolyposis colorectal cancer. Am J Med Genet C Semin Med Genet 2004, 129:91-99

20. Edelmann W, Umar A, Yang K, Heyer J, Kucherlapati M, Lia M, Kneitz B, Avdievich E, Fan K, Wong E, Crouse G, Kunkel T, Lipkin M, Kolodner RD, Kucherlapati R: The DNA mismatch repair genes Msh3 and Msh6 cooperate in intestinal tumor suppression. Cancer Res 2000, 60:803-807

21. Edelmann W, Yang K, Umar A, Heyer J, Lau K, Fan K, Liedtke W, Cohen PE, Kane MF, Lipford JR, Yu N, Crouse GF, Pollard JW, Kunkel $\mathrm{T}$, Lipkin M, Kolodner R, Kucherlapati R: Mutation in the mismatch repair gene Msh6 causes cancer susceptibility. Cell 1997, 91:467477

22. Andrew SE, McKinnon M, Cheng BS, Francis A, Penney J, Reitmair AH, Mak TW, Jirik FR: Tissues of MSH2-deficient mice demonstrate hypermutability on exposure to a DNA methylating agent. Proc Natl Acad Sc U S Am 1998, 95:1126-1130

23. Reitmair AH, Risley R, Bristow RG, Wilson T, Ganesh A, Jang A, Peacock J, Benchimol S, Hill RP, Mak TW, Fishel R, Meuth M: Mutator phenotype in Msh2-deficient murine embryonic fibroblasts. Cancer Res 1997, 57:3765-3771

24. Lowsky R, DeCoteau JF, Reitmair AH, Ichinohasama R, Dong WF, Xu $Y$, Mak TW, Kadin ME, Minden MD: Defects of the mismatch repair gene $\mathrm{MSH} 2$ are implicated in the development of murine and human lymphoblastic lymphomas and are associated with the aberrant expression of rhombotin-2 (Lmo-2) and Tal-1 (SCL). Blood 1997, 89: $2276-2282$

25. Reitmair AH, Schmits R, Ewel A, Bapat B, Redston M, Mitri A, Waterhouse $\mathrm{P}$, Mittrucker HW, Wakeham A, Liu B: MSH2 deficient mice are viable and susceptible to lymphoid tumours. Nat Genet 1995, 11: 64-70

26. Genschel J, Littman SJ, Drummond JT, Modrich P: Isolation of MutSbeta from human cells and comparison of the mismatch repair specificities of MutSbeta and MutSalpha. J Biol Chem 1998, 273: 19895-19901

27. Wei K, Kucherlapati R, Edelmann W: Mouse models for human DNA mismatch-repair gene defects. Trends Mol Med 2002, 8:346-353

28. Coleman WD, Tsongalis GJ: The role of genomic instability in the development of human cancer. The Molecular Basis of Human Can- 
cer. Edited by Coleman WD, Tsongalis GJ. Totawa, NJ, Humana Press, 2002, pp 115-142

29. Felton KEA, Gilchrist DM, Andrew SE: Constitutive deficiency in DNA mismatch repair. Clin Genetics 2007, 71:483-498

30. Miyashita K, Fujii K, Yamada Y, Hattori H, Taguchi K, Yamanaka T, Yoshida MA, Okamura J, Oda S, Muta K, Nawata H, Takayanagi R, Uike N: Frequent microsatellite instability in non-Hodgkin lymphomas irresponsive to chemotherapy. Leuk Res 2008, 32:1183-1195

31. Wang P, Wu F, Li L, Lai R, Young LC: Functional characterization of the kinase activation loop in nucleophosmin (NPM)-anaplastic lymphoma kinase (ALK) using tandem affinity purification and liquid chromatography-mass spectrometry. J Biol Chem 2010, 285:95-103

32. Umar A, Boland CR, Terdiman JP, Syngal S, de la CA, Ruschoff J, Fishel R, Lindor NM, Burgart LJ, Hamelin R, Hamilton SR, Hiatt RA, Jass J, Lindblom A, Lynch HT, Peltomaki P, Ramsey SD, RodriguezBigas MA, Vasen HF, Hawk ET, Barrett JC, Freedman AN, Srivastava S: Revised Bethesda Guidelines for hereditary nonpolyposis colorectal cancer (Lynch syndrome) and microsatellite instability. J Natl Cancer Inst 2004, 96:261-268

33. Wong YF, Cheung TH, Lo KW, Yim SF, Chan LK, Buhard O, Duval A, Chung TK, Hamelin R: Detection of microsatellite instability in endometrial cancer: advantages of a panel of five mononucleotide repeats over the National Cancer Institute panel of markers. Carcinogenesis 2006, 27:951-955

34. Oda S, Maehara Y, Ikeda Y, Oki E, Egashira A, Okamura Y, Takahashi I, Kakeji Y, Sumiyoshi Y, Miyashita K, Yamada Y, Zhao Y, Hattori H, Taguchi K, Ikeuchi T, Tsuzuki T, Sekiguchi M, Karran P, Yoshida MA: Two modes of microsatellite instability in human cancer: differential connection of defective DNA mismatch repair to dinucleotide repeat instability. Nucleic Acids Res 2005, 33:1628-1636

35. Plaschke J, Engel C, Kruger S, Holinski-Feder E, Pagenstecher C, Mangold E, Moeslein G, Schulmann K, Gebert J, von Knebel DM, Ruschoff J, Loeffler M, Schackert HK: Lower incidence of colorectal cancer and later age of disease onset in 27 families with pathogenic MSH6 germline mutations compared with families with MLH1 or MSH2 mutations: the German Hereditary Nonpolyposis Colorectal Cancer Consortium. J Clin Oncol 2004, 22:4486-4494

36. Nicolaides NC, Littman SJ, Modrich P, Kinzler KW, Vogelstein B: A naturally occurring hPMS2 mutation can confer a dominant negative mutator phenotype. Mol Cell Biol 1998, 18:1635-1641

37. Karran P: Thiopurines, DNA damage, DNA repair and therapy-related cancer. Br Med Bull 2006, -80:153-17079

38. Yan T, Berry SE, Desai AB, Kinsella TJ: DNA mismatch repair (MMR) mediates 6-thioguanine genotoxicity by introducing single-strand breaks to signal a G2-M arrest in MMR-proficient RKO cells. Clin Cancer Res 2003, 9:2327-2334

39. Boccalatte FE, Voena C, Riganti C, Bosia A, D'Amico L, Riera L, Cheng M, Ruggeri B, Jensen ON, Goss VL, Lee K, Nardone J, Rush J, Polakiewicz RD, Comb MJ, Chiarle R, Inghirami G: The enzymatic activity of 5-aminoimidazole-4-carboxamide ribonucleotide formyltransferase/IMP cyclohydrolase is enhanced by NPM-ALK: new insights in ALK-mediated pathogenesis and the treatment of ALCL. Blood 2009, 113:2776-2790

40. Christmann M Kaina B: Nuclear translocation of mismatch repair proteins $\mathrm{MSH} 2$ and $\mathrm{MSH} 6$ as a response of cells to alkylating agents. J Biol Chem 2000, 275:36256-36262

41. Christmann M, Tomicic MT, Kaina B: Phospohorylation of mismatch repair protiens $\mathrm{MSH} 2$ and $\mathrm{MSH} 6$ affecting MutS-alpha mismatch binding activity. Nucleic Acids Res 2002, 30:1959-1966

42. Iwanaga R, Komori H, Ohtani K: Differential regulation of expression of the mammalian DNA repair genes by growth stimulation. Oncogene 2004, 23:8581-8590

43. Wilson TM, Ewel A, Duguid JR, Eble JN, Lescoe MK, Fishel R, Kelley MR: Differential cellular expression of the human MSH2 repair enzyme in small and large intestine. Cancer Res 1995, 55:5146-5150

44. Knudsen NO, Andersen SD, Lutzen A, Nielsen FC, Rasmussen LJ: Nuclear translocation contributes to regulation of DNA excision repair activities. DNA Repair (Amst) 2009, 8:682-689

45. Hong Z, Jiang J, Hashiguchi K, Hoshi M, Lan L, Yasui A: Recruitment of mismatch repair proteins to the site of DNA damage in human cells. J Cell Sci 2008, 121:3146-3154
46. Ambrogio C, Voena C, Manazza AD, Piva R, Riera L, Barberis L, Costa C, Tarone G, Defilippi P, Hirsch E, Boeri EE, Mohammed S, Jensen ON, Palestro G, Inghirami G, Chiarle R: p130Cas mediates the transforming properties of the anaplastic lymphoma kinase. Blood 2005, 106:3907-3916

47. Dierov J, Sanchez PV, Burke BA, Padilla-Nash H, Putt ME, Ried T, Carroll $\mathrm{M}$ : $\mathrm{BCR} / \mathrm{ABL}$ induces chromosomal instability after genotoxic stress and alters the cell death threshold. Leukemia 2009, 23:279286

48. Fernandes MS, Reddy MM, Gonneville JR, DeRoo SC, Podar K, Griffin JD, Weinstock DM, Sattler M: BCR-ABL promotes the frequency of mutagenic single-strand annealing DNA repair. Blood 2009, 114:1813-1819

49. Poplawski T, Blasiak J: BCR/ABL downregulates DNA-PK(CS)-dependent and upregulates backup non-homologous end joining in leukemic cells. Mol Biol Rep 2010, 37:2309-2315

50. Lal MA, Bae D, Camilli TC, Patierno SR, Ceryak S: AKT1 mediates bypass of the G1/S checkpoint after genotoxic stress in normal human cells. Cell Cycle 2009, 8:1589-1602

51. Penserga ET, Skorski T: Fusion tyrosine kinases: a result and cause of genomic instability. Oncogene 2007, 26:11-20

52. Stoklosa T, Poplawski T, Koptyra M, Nieborowska-Skorska M, Basak G, Slupianek A, Rayevskaya M, Seferynska I, Herrera L, Blasiak J, Skorski T: BCR/ABL inhibits mismatch repair to protect from apoptosis and induce point mutations. Cancer Res 2008, 68:2576-2580

53. Buhard O, Suraweera N, Lectard A, Duval A, Hamelin R: Quasimonomorphic mononucleotide repeats for high-level microsatellite instability analysis. Dis Markers 2004, 20:251-257

54. Brennetot C, Buhard O, Jourdan F, Flejou JF, Duval A, Hamelin R: Mononucleotide repeats BAT-26 and BAT-25 accurately detect MSI-H tumors and predict tumor content: implications for population screening. Int J Cancer 2005, 113:446-450

55. Buhard O, Cattaneo F, Wong YF, Yim SF, Friedman E, Flejou JF, Duval A, Hamelin R: Multipopulation analysis of polymorphisms in five mononucleotide repeats used to determine the microsatellite instability status of human tumors. J Clin Oncol 2006, 24:241-251

56. Hodges KB, Vnencak-Jones CL, Larson RS, Kinney MC: Rarity of genomic instability in pathogenesis of systemic anaplastic large cell lymphoma (ALCL) in immunocompetent patients. Hum Pathol 1999, 30:173-177

57. Hernandez-Pigeon H, Quillet-Mary A, Louat T, Schambourg A, Humbert O, Selves J, Salles B, Laurent G, Lautier D: hMutS alpha is protected from ubiquitin-proteasome-dependent degradation by atypical protein kinase C zeta phosphorylation. J Mol Biol 2005, 348:63-74

58. Hernandez-Pigeon H, Laurent G, Humbert O, Salles B, Lautier D: Degadration of mismatch repair hMutSalpha heterodimer by the ubiquitin-proteasome pathway. FEBS Lett 2004, 562:40-44

59. Ollila S, Sarantaus L, Kariola R, Chan P, Hampel H, Holinski-Feder E, Macrae F, Kohonen-Corish M, Gerdes AM, Peltomaki P, Mangold E, de la CA, Greenblatt M, Nystrom M: Pathogenicity of MSH2 missense mutations is typically associated with impaired repair capability of the mutated protein. Gastroenterology 2006, 131:1408-1417

60. Pepponi R, Graziani G, Falcinelli S, Vernole P, Levati L, Lacal PM, Pagani E, Bonmassar E, Jiricny J, D'Atri S: hMSH3 overexpression and cellular response to cytotoxic anticancer agents. Carcinogenesis 2001, 22:1131-1137

61. Rozen S, Skaletsky HJ: Primer3 on the WWW for general users and for biologist programmers. Bioinformatics Methods and Protocols: Methods in Molecular Biology. Edited by S Krawetz, S Misener. Totowa, NJ, Humana Press, 2000, pp 365-386

62. Umetani N, Sasaki S, Watanabe T, Ishigami H, Ueda E, Nagawa $H$ : Diagnostic primer sets for microsatellite instability optimized for a minimal amount of damaged DNA from colorectal tissue samples. Ann Surg Oncol 2000, 7:276-280

63. Findeisen P, Kloor M, Merx S, Sutter C, Woerner SM, Dostmann N, Benner A, Dondog B, Pawlita M, Dippold W, Wagner R, Gebert J, von Knebel DM: T25 repeat in the $3^{\prime}$ untranslated region of the CASP2 gene: a sensitive and specific marker for microsatellite instability in colorectal cancer. Cancer Res 2005, 65:8072-8078 